NASA Technical Memorandum 80113

\title{
STATUS OF KNOWLEDGE OF SONIC BOOMS
}

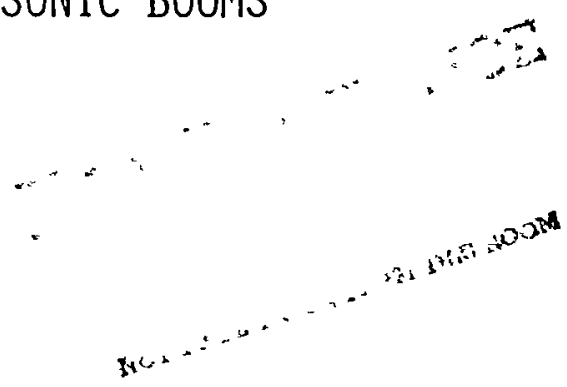

Domenic J, Maglieri, Harry $W$. Carlson, and HaRVEY H. HubBard

JUNE 1979

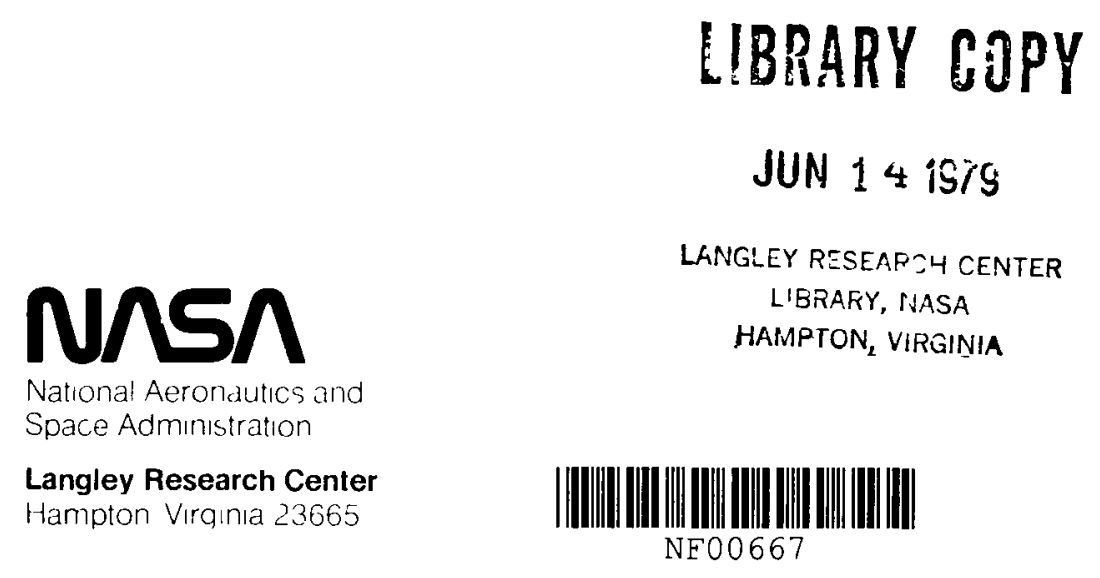




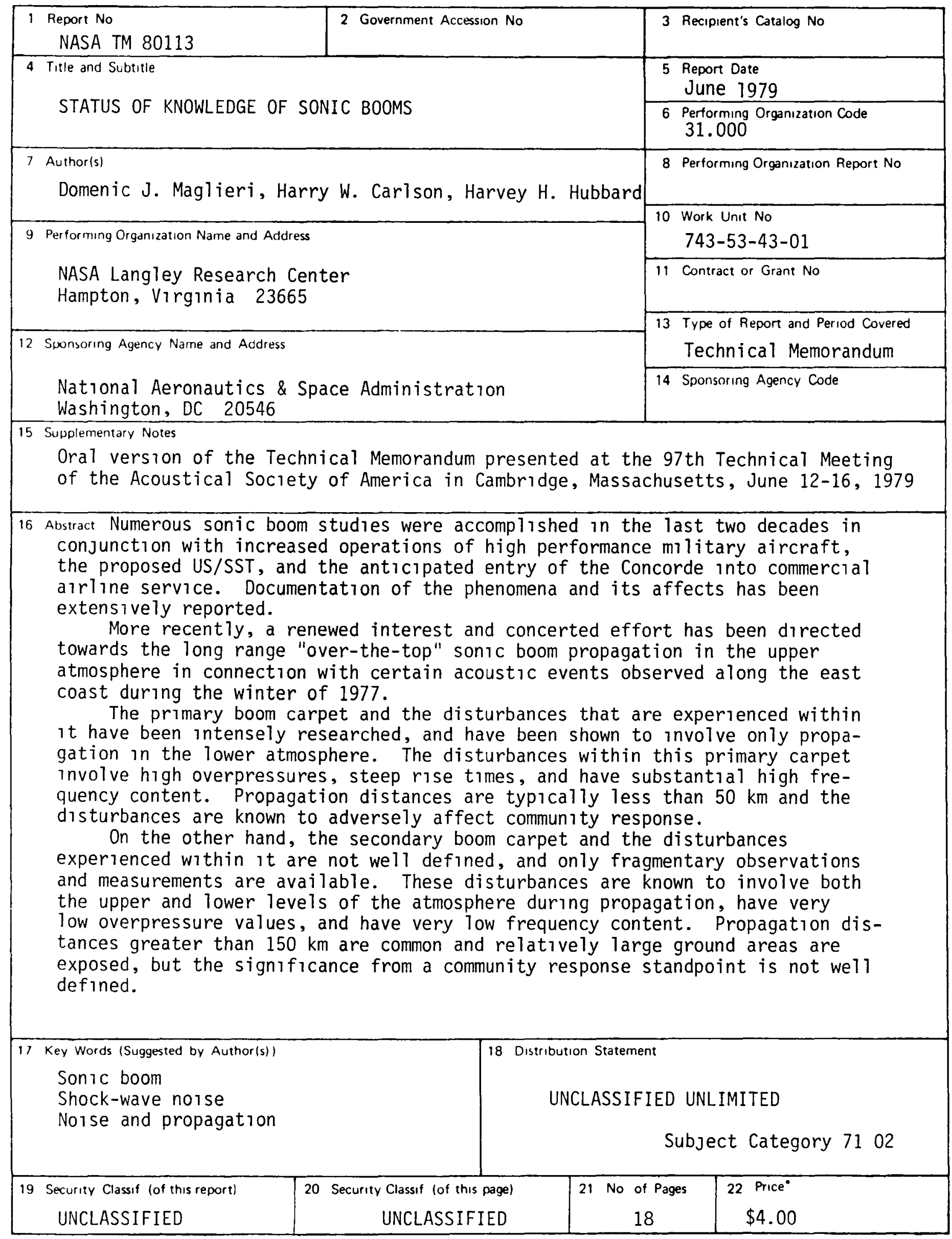

* For sale by the National Technical Information Service Springfield Virginia 22161 


\title{
STATUS OF KNOWLEDGE OF SONIC BOOMS
}

\author{
by Domenic J. Maglieri, Harry W. Carlson, \\ and Harvey $H$. Hubbard \\ Langley Research Center \\ Hampton, Virginia 23665
}

\section{SUMMARY}

Numerous sonic boom studies were accomplished in the last two decades in conjunction with increased operations of high performance military aircraft, the proposed US/SST, and the anticipated entry of the Concorde into commercial airline service. Documentation of the phenomena and its affects has been extensively reported.

More recently, a renewed interest and concerted effort has been directed towards the long range "over-the-top" sonic boom propagation in the upper atmosphere in connection with certain acoustic events observed along the east coast during the winter of 1977.

The primary boom carpet and the disturbances that are experienced within it have been intensely researched, and have been shown to involve only propagation in the lower atmosphere. The disturbances within this primary carpet involve high overpressures, steep rise times, and have substantial high frequency content. Propagation distances are typically less than $50 \mathrm{~km}$ and the disturbances are known to adversely affect community response.

On the other hand, the secondary boom carpet and the disturbances experienced within it are not well defined, and only fragmentary observations and measurements are avallable. These disturbances are known to involve both the upper and lower levels of the atmosphere during propagation, have very low overpressure values, and have very low frequency content. Propagation distances greater than $150 \mathrm{~km}$ are common and relatively large ground areas are exposed, but the significance from a community response standpoint is not well defined.

\section{INTRODUCTION}

Numerous sonic boom studies were accomplished in the last two decades in conjunction with increased operations of high performance military aircraft, the proposed US/SST, and the anticipated entry of the supersonic Concorde into commercial airline service. Documentation of the phenomena and its affects has been extensively reported (ref. 1-6 for example). 
Sonic booms continue to be a serious community acceptance problem for airplane operations at supersonic speeds. This problem has been highlighted by the recent experience derived from Concorde operations (ref. 7). More recently, a renewed interest and concerted effort has been directed towards the long range "over-the-top" sonic boom propagation in the upper atmosphere in connection with certain acoustic events observed along the east coast during the winter of 1977 (ref. 8-12).

The purpose of this paper is to briefly summarize the status of sonic boom technology with particular emphasis on the more recent research results. Included are definitions of the boom carpets, both primary and secondary, a discussion of existing experience with primary booms including the status of overpressure predictions and boom minimization methodology through airplane design, an indication of the boom waveforms and audibility, and a discussion of focus booms resulting from aircraft maneuvers as well as the effect of abnormal atmospheric conditions on these maneuver booms.

\section{DEFINITION OF SONIC BOOM CARPETS}

Figure 1 shows schematically the nature of the sonic boom carpets for a mission where the aircraft flies a large portion of the distance supersonically and without maneuvers. Two ground exposure patterns in which booms are observed are shown. The primary boom carpet contains the normally observed sonic boom overpressures and results from wave propagation through only that part of the atmosphere below the aircraft. Beyond the primary carpet exists a region in which no sonic booms are observed. The secondary boom carpet involves the portion of the atmosphere above the airplane as well as that below the airplane. The exposed areas are more remote from the ground track and the overpressure levels are much less intense than in the primary carpet.

The manner in which the atmosphere above and below the airplane is involved in developing the primary and secondary boom carpets is shown in more detail in the ray diagram of figure 2. On the right-hand side of figure 2 are indicated examples of temperature and wind profiles for a normal atmosphere. The point to note is that there is a portion of the higher atmosphere in which the temperature increases as altitude increases and the associated wave propagation speed thus increases compared to that in the lower portions of the atmosphere. Similarly, the wind may participate in such a way as to further increase the wave propagation speed in certain directions.

On the left-hand side of figure 2 is an example ray diagram for an aircraft at $20 \mathrm{~km}$ altitude traveling in a direction towards the viewer. The downward propagating rays, shown by the solid lines, impact the ground to form the primary carpet region, as indicated in the figure. At some point, about $40 \mathrm{~km}$ in the example shown, the rays refract away from the ground and thus define the lateral extent of the primary carpet.

Also indicated is a secondary carpet region at about $120 \mathrm{~km}$ to $170 \mathrm{~km}$ from the flight track in which the dashed line rays impact. These dashed line rays are seen to arrive in two different ways, that 15 , they either travel directly 
to the secondary carpet region as a result of bending in the upper atmosphere or they may first impinge in the primary carpet region, reflect upward from the surface, and then subsequently bend downward after traveling through a portion of the upper atmosphere. The representation of the secondary carpet region in this illustration is probably over simplified because there is reason to believe that it may consist of several well defined impact areas (see for example reference 10 and 11). Variations in atmospheric wind and temperature profiles, however, could cause these impact areas to lose their identities. Some of the rays above the airplane with the vertical ray paths may travel in such a way that they are dissipated without ever approaching the ground.

\section{SOURCE CHARACTERISTICS}

The overpressures experienced in the primary and secondary carpet areas not only depend upon the atmospheric characteristics and distances traveled by the shock waves, but upon their initial strength and directivity. Some of the characteristics of the pressure signatures within the flow field surrounding the XB-70 airplane are shown in figure 3 (from reference 13). These in-flight measurements were obtained by probing the flow field above and below the $X B-70$ with an instrumented aircraft. The $X B-70$ was flying at $M=1.5$ at $11.3 \mathrm{~km}$ altitude and in-flight surveys were made at $0.6 \mathrm{~km}$ above and $0.6 \mathrm{~km}$ and $1.5 \mathrm{~km}$ below the aircraft. Also shown is the corresponding signature measured at ground level.

The measured signatures are shaded to highlight the individual pressure peaks. These pressure peaks are associated with details of the airplane geometry (wings, inlets, canopy, empennage, etc.). It can be seen that more complex signatures are measured close in to the aircraft and that the individual shock waves from the alrcraft tend to coalesce as distance from the aircraft increases. It can also be seen that the shock wave signature above the aircraft differs markedly (shape and amplitude) from that below the aircraft at a comparable distance. This results from the difference in the detailed geometry of the arrplane and the manner in which the volume and lift components interact.

\section{PRIMARY CARPET MEASUREMENTS AND PREDICTIONS}

During the last two decades, there has been a considerable number of studies aimed at defining the peak amplitudes (peak overpressures) of the direct carpet sonic boom signatures for a wide range of vehicles and flight conditions and a summary of these results are shown in figure 4 . Predicted and measured "on-track" sonic boom overpressures are plotted as a function of altitude for several aircraft of various sizes and weights along with measured data for the launch and reentry phases of the Apol10 15, 16, and 17 spacecraft vehicles (ref. 14). Good correlation exists between measured and predicted values of overpressure for the aircraft cases. The sonic boom levels, in general, increased with increasing aircraft size and decreased with increasing altitude. The theory is shown to be valid for direct booms of conventional aircraft. 
For the case of measurements made during the reentry of spacecraft flights, the measured data are consistent with data obtained for aircraft in that they appear to be comparable in magnitude to extrapolated levels for fighter or medium bomber aircraft and display a similar decrease with increasing altitude.

The measured overpressures for the launch and ascent portion of spacecraft flights, in general, indicate the same trend of decreasing pressure with increasing altitude. However, the magnitudes of the overpressure values are considerably higher than those of the reentry case. Since the size of the launch vehicle is considerably greater than the reentry vehicle, higher boom levels can be expected. The largest portion of the increased overpressure from launch vehicles results from the "effective body" produced by the rocket exhaust plume. Note that disturbances can be measured at ground level for a flight vehicle operating at altitudes up to about $180 \mathrm{~km}$ (also see ref. 15). Simplified methods for prediction of spacecraft sonic boom are discussed in reference 16. It was not possible to show on this figure prediction data for spacecraft because $1 t$ is not simply a function of altitude. The prediction $1 \mathrm{~s}$, however, in general agreement with the measured data, but do not show as good a degree of correlation as for the airplane data.

Considerable attention has also been given to defining the lateral extent of the primary boom carpet for steady flights of aircraft at various Mach numbers and altitudes. The calculated and measured primary carpet data for 13 flights of the XB-70 in the Mach number range of 2.0 and at $18.4 \mathrm{~km}$ altitude is shown in figure 5 (ref. 5). Also shown are schematic 117 ustrations of the types of sonic boom signatures or waveforms observed at various distances from the ground track. This data is typical of other aircraft and operating conditions.

At the top of the figure is shown schematically an approaching supersonic alrplane along with the downward propagating rays (similar to the sketch shown in figure 2). The extent of the direct carpet is the point at which the ray refracts away from the ground (the "cutoff" distance) and this point, which is independent of airplane type, is a function of the aircraft altitude, and Mach number, and the characteristics of the atmosphere below the alrcraft.

Good agreement is noted to exist between theory and experiment for both overpressure level and lateral cutoff point. The highest overpressures are noted to occur near the ground track and are associated with an $\mathrm{N}$-wave type signature. As lateral distance increases, the overpressure decreases. The waveform loses its $\mathrm{N}$-wave characteristics as the lateral cutoff point is approached and the booms are then observed as "rumbles."

\section{SONIC-BOOM MINIMIZATION}

The discussions thus far have related to the on-track and lateral sonic-boom pressure distributions and it has been shown that sonic-boom effects are minimized through increased distance between the airplane and the ground. Minimizing the sonic booms through arrplane design modifications has also been investigated (refs. 3, 4, and 17). Some of the approaches that have been considered are 7 llustrated in the sketches of figure 6 . Sonic-boom minimization 
can be achieved through a reduction in the overpressure or an increase in the signature rise time, each of these parameters being significant with regard to human and structural response (ref. 18, 19, and 20). As illustrated in the left-hand sketches of figure 6 , reduced overpressures can be obtained by reducing the size of the airplane (that is, lower airplane weight and volume) or by proper shaping of the airplane geometry to provide a modified ( $f$ lat top) signature. These two approaches have been given much consideration in the past and reduction in bow-wave overpressures of the order of about 30 percent to perhaps as much as 40 percent seems obtainable. Other minimization techniques involving increasing rise times have also been investigated (ref. 21-22). If the rise time of the signature could be increased to the point where a sine wave would result instead of an $\mathrm{N}$-wave, the sine-wave pressure signature would not be audible to an outdoor observer although building responses would still result. In order to obtain even small values of finite rise times the airplane length would have to be increased by at least a factor of 3 (to about $310 \mathrm{~m}$ $(1000 \mathrm{ft})$ ) over the greatest length now being considered. This in itself is a very impractical approach. Another means would be to alter the airstream so that the same beneficial effects associated with the increased length are obtained. This could be accomplished by the addition of heat or other forms of energy. Studies (refs. 4 and 22) regarding the airstream alteration or "phantom body" concept suggest that large amounts of heat or energy are required (at least the equivalent of the output from four more propulsion engines) to obtain finite rise-time signatures. This latter approach, therefore, also appears to be impractical.

As a result of past and current efforts in boom minimization it is generally agreed that the nominal cruise sonic boom signatures can be modified through airplane design (1ift and volume distributions). The analytical tools for defining the required airplane characteristics are available and have been validated by means of wind tunnel experiments on small wing-body configurations representing transport aircraft. Means for evaluating the tradeoffs for boom minimization in terms of an actual airplane design are avallable.

\section{WAVE FORM CHARACTERISTICS AND AUDIBILITY}

For many military operations and in particular the over water fioght of the Concorde, the waveform characteristics of the boom signatures can vary widely at the different observation points as indicated in figure 7 . In the region of the primary boom carpet, on or near the ground track, typically $\mathrm{N}$-wave type signatures are observed and these are usually of the order of 50 $\mathrm{n} / \mathrm{m}^{2}$ to $100 \mathrm{n} / \mathrm{m}^{2}$ in amp 7 tude (see figure 4) and from $100 \mathrm{mi} 11 \mathrm{iseconds}$ to $300 \mathrm{mlll} i \mathrm{~seconds}$ in duration. At the fringes of the primary boom carpet, near the lateral cutoff, the signatures degenerate into weak sound waves and they lose their $\mathrm{N}$-wave characteristics. In the region of the secondary boom carpet, the disturbances tend to be very weak in intensity (of the order .05 $\mathrm{n} / \mathrm{m}^{2}$ to $0.5 \mathrm{n} / \mathrm{m}^{2}$ ) but persist over longer periods of time (see ref. $9-12$ ). It should be noted that higher overpressure $\mathrm{N}$-wave sonic booms cause community acceptance problems. On the other hand, the lateral cutoff booms and the secondary carpet booms, which do not have an $\mathrm{N}$-wave character, tend to be more of a currosity and are not apt to be the source of serious community response 
problems. The direct carpet lateral cutoff booms are usually observed as low rumbles or rolling thunder. Secondary carpet booms, however, are generally not audible $(0.1 \mathrm{~Hz}$ to $1.0 \mathrm{~Hz})$ but can cause bullding vibrations which are readily observed.

\section{EFFECTS OF AIRPLANE MANEUVERS}

Another type of pressure signature, that of a focus boom, shown in the lower left of figure 7 , is one which can be observed when any aircraft accelerates from subsonic to supersonic speeds. These "transition" focus booms are followed by regions on the ground in which multiple booms are observed. The focus booms are enhancements of the booms generated in steady level flight operations.

Son1c-boom enhancement can result from a variety of airplane maneuvers. In the upper portion of figure 8 are illustrated three types of maneuvers which could result in pressure buildups at ground level (a longitudinal acceleration, a $90^{\circ}$ turn, and a pushover maneuver). In each maneuver, pressure buildups occur in the localized regrons suggested by the shaded areas shown in the sketches. It should be pointed out that although the airplane and shock waves are moving, the areas on the ground in which pressure buildups occur are fixed and do not move with the airplane. The pressure buildups in these focus areas are a function of the type of maneuver and acceleration involved. As noted earlier, pressure buildups will always result for the longitudinal maneuver when the airplane accelerates from subsonic to supersonic speeds. The effects can be minimized by reducing acceleration rates. The pressure buildup areas associated with turns and pushover maneuvers can be minimized or avoided by reducing acceleration or by simply avoiding the maneuver.

The overpressure buildups, or focus factors, in these maneuvers are shown as a function of airplane acceleration in the lower part of figure 8 . The information contained in this figure is a result of flight experiments conducted in the USA, and in France (see ref. 5). The data points shown represent the highest levels measured thus far for longltudinal accelerations and turning maneuvers. The hatched boundary, therefore, would represent the current upper bound values. At the lower values of acceleration, which are usually associated with longitudinal accelerations, the overpressure in the focus is of the order of from about 2 to 5 times the nominal overpressure for steady level flight at the same altitude and Mach number. For a turn maneuver involving a $2 \mathrm{~g}$ acceleration, a focus factor of up to 9 has been measured.

In scheduled commercial operations, longitudinal acceleration from subsonic to supersonic speeds is the only maneuver of significance from a ground exposure point of view. The main sources of multiple booms and focus booms are associated with military training maneuvers. Considerable planning and care is taken to conduct these maneuvers in designated areas that are located remotely from populated areas. In some instances, however, the atmospheric conditions are such as to cause the shock waves to impact the populated areas. Figure 9 illustrates these two boom exposure situations. Aircraft are shown in various maneuvering situations of level accelerations, pull-ups, and dives, well off 
from the coastline and within the designated operational area. Under normal atmospheric situations, as in the case illustrated in the left hand sketch of figure 9, the primary booms propagate along the solid rays directly to the surface as indicated by the shaded regions. Other disturbances will propagate along the dashed 17 ne ray and are refracted upwards away from the populated area. Nonstandard weather conditions involving extreme temperature inversions and unusual wind structures, can result in the ray path situation shown on the right hand side of figure 9. In this case, the wave propagation speed profile in the atmosphere is such that the sonic booms which previously impacted short of the populated area are projected further forward and thus can directly impact the surface over an extended distance as suggested by the shaded regron.

\section{CONCLUDING REMARKS}

The primary boom carpet and the disturbances that are experienced within it have been intensely researched, and have been shown to involve only propagation in the lower atmosphere. The disturbances within this primary carpet involve high overpressures, steep rise times, and have substantial high frequency content. Propagation distances are typically less than $50 \mathrm{~km}$ and the disturbances are known to adversely community response.

On the other hand, the secondary boom carpet and the disturbances experienced within it are not well defined, and only fragmentary observations and measurements are avallable. These disturbances are known to involve both the upper and lower levels of the atmosphere during propagation, have very low overpressure values, and have very low frequency content. Propagation distances greater than $150 \mathrm{~km}$ are common and relatively large ground areas are exposed, but the significance from a community response standpoint is not well defined. 


\section{REFERENCES}

1. Anon: Proceedings of the Sonic Boom Symposium. J. Acoust. Soc. Amer., Vol. 39, No. 5, Pt. 2, May 1966, pp. S1-S80.

2. Seebass, A. R., ed.: Sonic Boom Research. NASA SP-147, 1967.

3. Schwartz, Ira R., ed.: Second Conference on Sonic Boom Research. NASA SP-180, 1968.

4. Schwartz, Ira R., ed.: Third Conference on Sonic Boom Research. NASA SP$255,1971$.

5. Maglierı, Domenic J.; Carlson, Harry W.; and McLeod, Norman J.: Status of Studies on Sonic Boom. NASA Aircraft Safety and Operating Problems, Vol. 1, NASA SP-270, 1971, pp. 439-456.

6. H. S. Ribner and H. H. Hubbard, eds. Proceedings of the Second Sonic Boom Symposium. Acoust. Soc. Amer., Nov. 1970, Amer. Inst. of Physics, New York, 1972.

7. Anon. Concorde Monitoring - John F. Kennedy International Airport. U. S. Dept. Transportation, FAA. August 1978.

8. Anon: NRL Investigation of East Coast Acoustic Events 2 December 1977 15 February 1978. (March 1978).

9. Gardner, John H.; and Rogers, Peter H.. Thermospheric Propagation of Sonic Booms from the Concorde Supersonic Transport. NRL Memorandum Report 3904. Feb. 14, 1979.

10. Balachandian, N. K.; Donn, W. L., and Rind, D. H.: Concorde Sonic Booms as an Atmospheric Probe. Science, 197, 47-49 (July 1977).

11. Donn, William L.: Exploring the Atmosphere with Sonic Booms. American Screntist, Vol. 66, pp. 724-733, Nov.- Dec. 1978.

12. Liszka, Ludwik: Long - Distance Focusing of Concorde Sonic Boom. J. Acoust. Soc. Amer., Vol. 64, llo. 2, pp. 633-635, Aug. 1978.

13. Maglierı,D. J.; Huckel, V., Henderson, H. R.; and Putman, T.: Preliminary Results of XB-70 Sonic Boom Field Tests During National Sonic Boom Evaluation Program. NASA LWP - 382, March 9, 1967.

14. Henderson, Herbert R.; and Hilton, David A.: Sonic Boom Measurements in the Focus Region During the Ascent of Apol10 17. NASA TN D - 7806, Dec. 1974.

15. Cotten, Donald; and Donn, William L. Sounds from Apollo Rockets in Space. Scrence, Vo1. 171, pp. 565-567, 12 February 1971. 
16. Carlson, Harry W.: Simplified Sonic-Boom Predictions. NASA TP-1122, March 1978.

17. Mack, Robert J.; and Darden, Christine M.: Some Effects of Applying Sonic Boom Minimization to Supersonic Cruise Aircraft Design. AIAA 5th Aeroacoustic Conference, Seattle, WA, March 12-14, 1979. Preprint No. 79-0652.

18. Stanford Res. Inst.: Sonic Boom Experiments at Edwards Air Force Base. NSBE0-1-67 (Contract AF 49(638)-1758), NTIS, U. S. Dept. Com., July 28, 1967. (Available from DDC as AD 655310 ).

19. Niedzwiecki, A.; and Ribner, H. R.: Subjective Loudness of N-wave Sonic Boom Waveforms. J. Acoust. Soc. Amer., Vol. 64, No. 6, pp. 1622-1626, Dec. 1978.

20. Niedzwiecki, A., and Ribner, H. R.: Subjective Loudness of "Minimized" Sonic Boom Waveforms. J. Acoust. Soc. Amer., Vol. 64, No. 6, pp. 16221626, Dec. 1978.

21. McLean, F. Edward; Carlson, Harry W.; and Hunton, Lynn W.: Sonic Boom Characteristics of Proposed Supersonic and Hypersonic Airplanes. NASA TN D-3587, 1966.

22. Miller, David S.; and Carlson, Harry W.: A Study of the Application of Heat as Force Fields to the Sonic Boom Minimization Problem. NASA TN D-5582, 1969. 


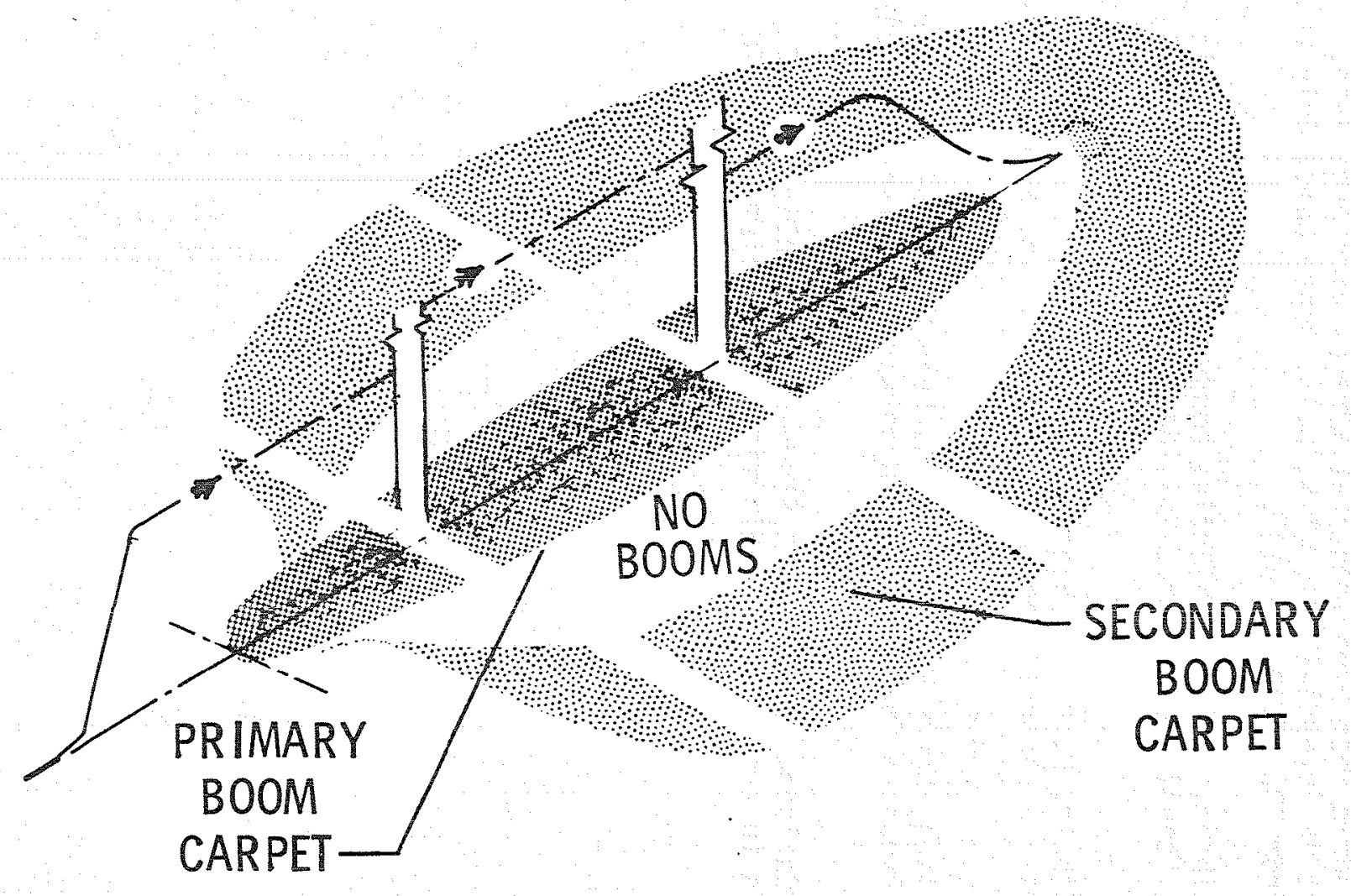

Figure 1.- Schematic illustration of the nature and extent of the sonic boom ground exposure carpets associated with supersonic aircraft operations. 


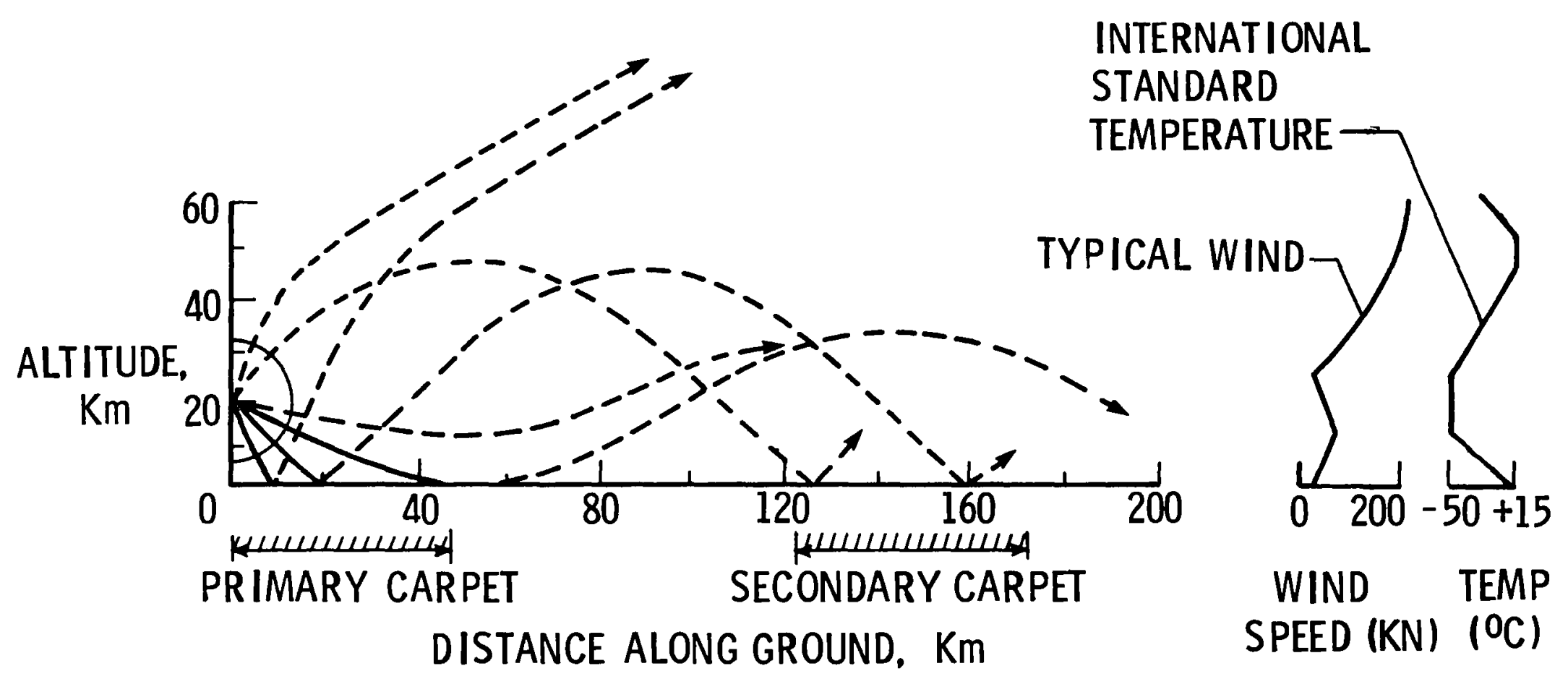

Figure 2.- Schematic diagram illustrating the propagation paths of sonic boom disturbances from an aircraft and the associated ground exposure carpets. 


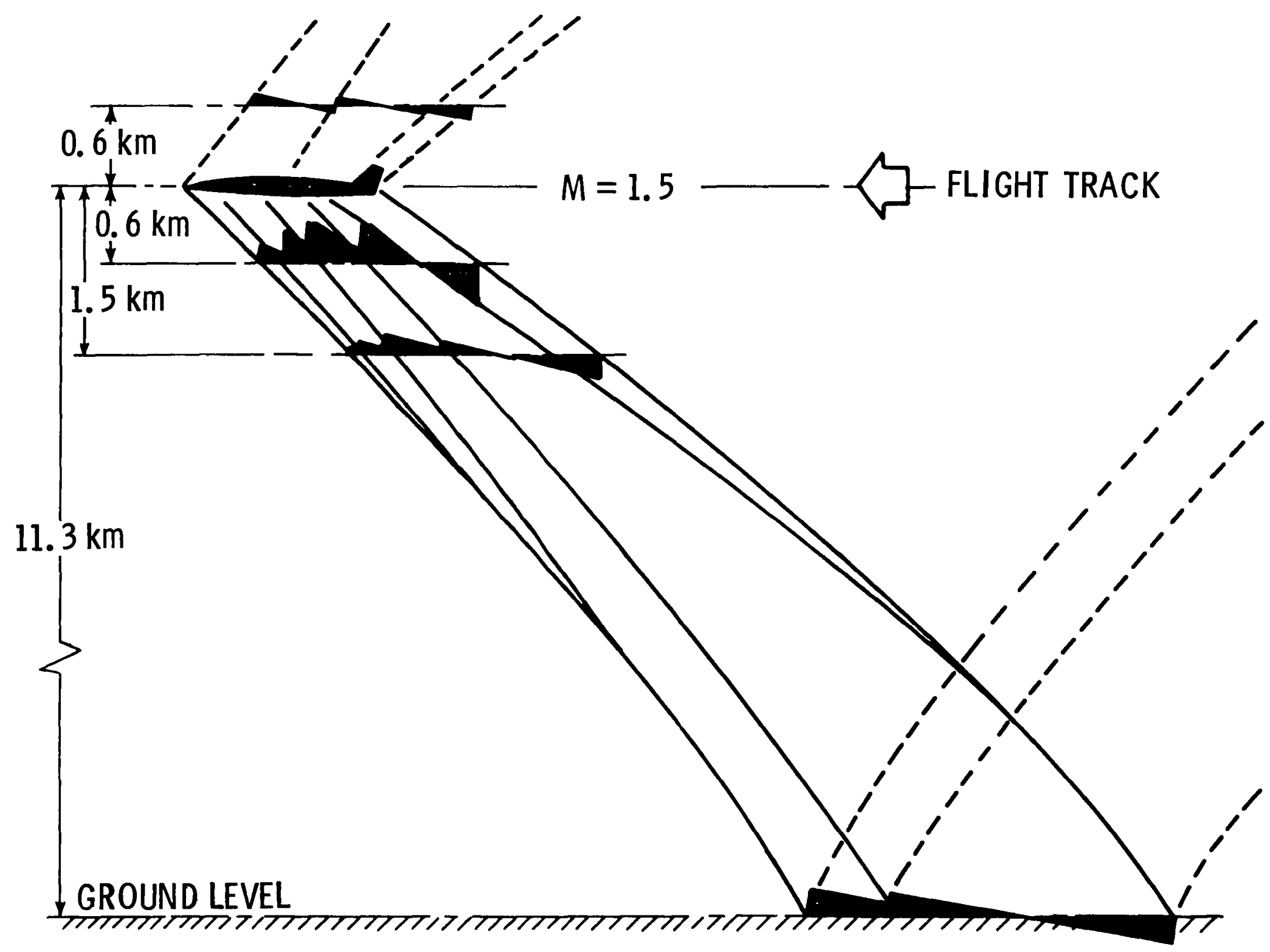

Figure 3.- Measured pressure signatures in the flow field of the XB-70 aircraft in flight at $M=1.5$. 


\section{ON TRACK MEASUREMENTS}

SONIC BOOM
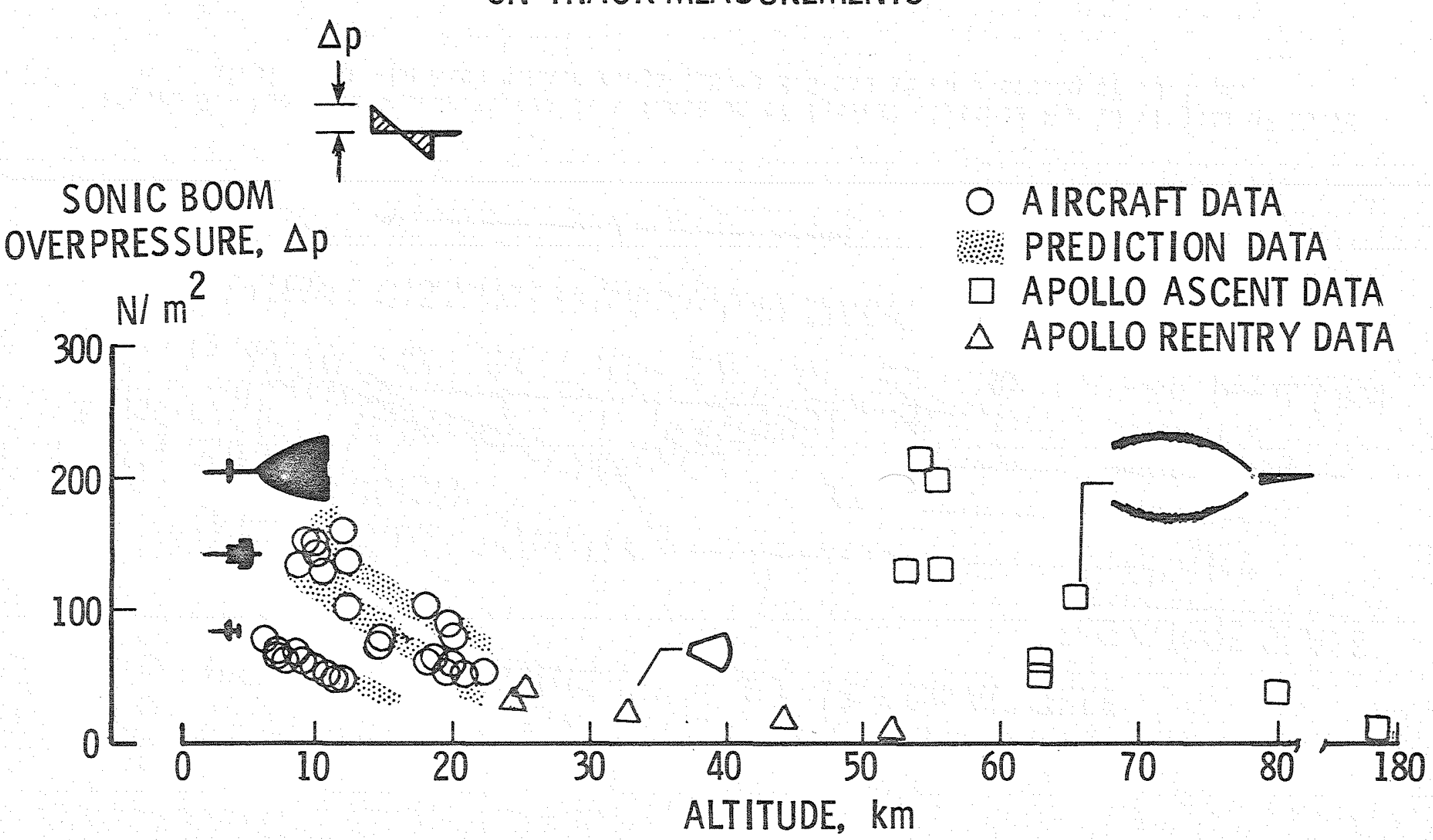

Figure 4.- A comparison of measured and predicted sonic boom overpressures in the primary carpet area for several aircraft and spacecraft. 


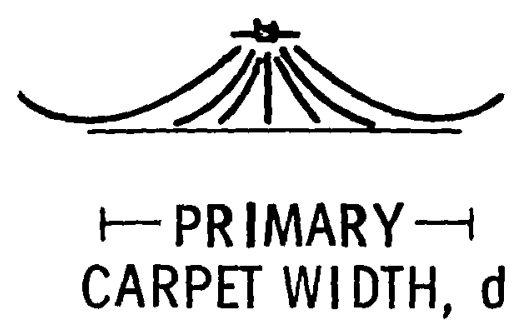

O EXPER IMENT, 13 FLIGHTS @ $M=2.018 .4 \mathrm{Km}$ ALTITUDE

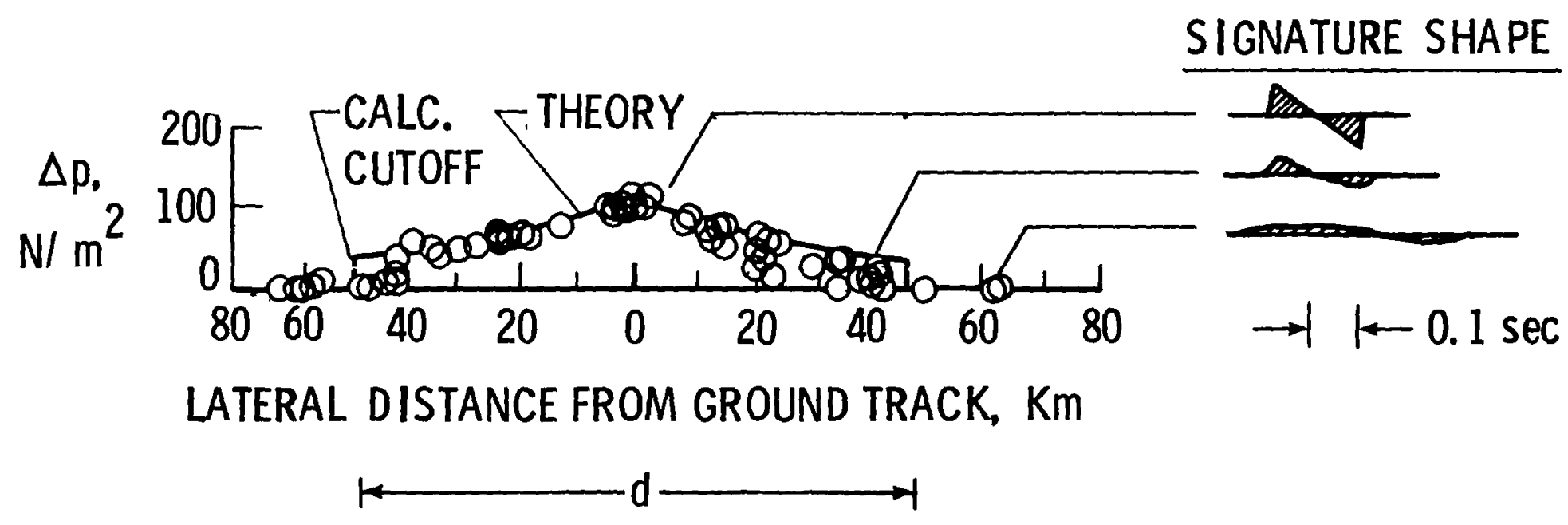

Figure 5.- Measured overpressures as a function of lateral distance for 13 flights of $X B-70$ airplane in the Mach number range 1.8 to 2.5 and at an altitude of $18.4 \mathrm{~km}$. 


\section{REDUCED OVERPRESSURE INCREASED RISE TIME}

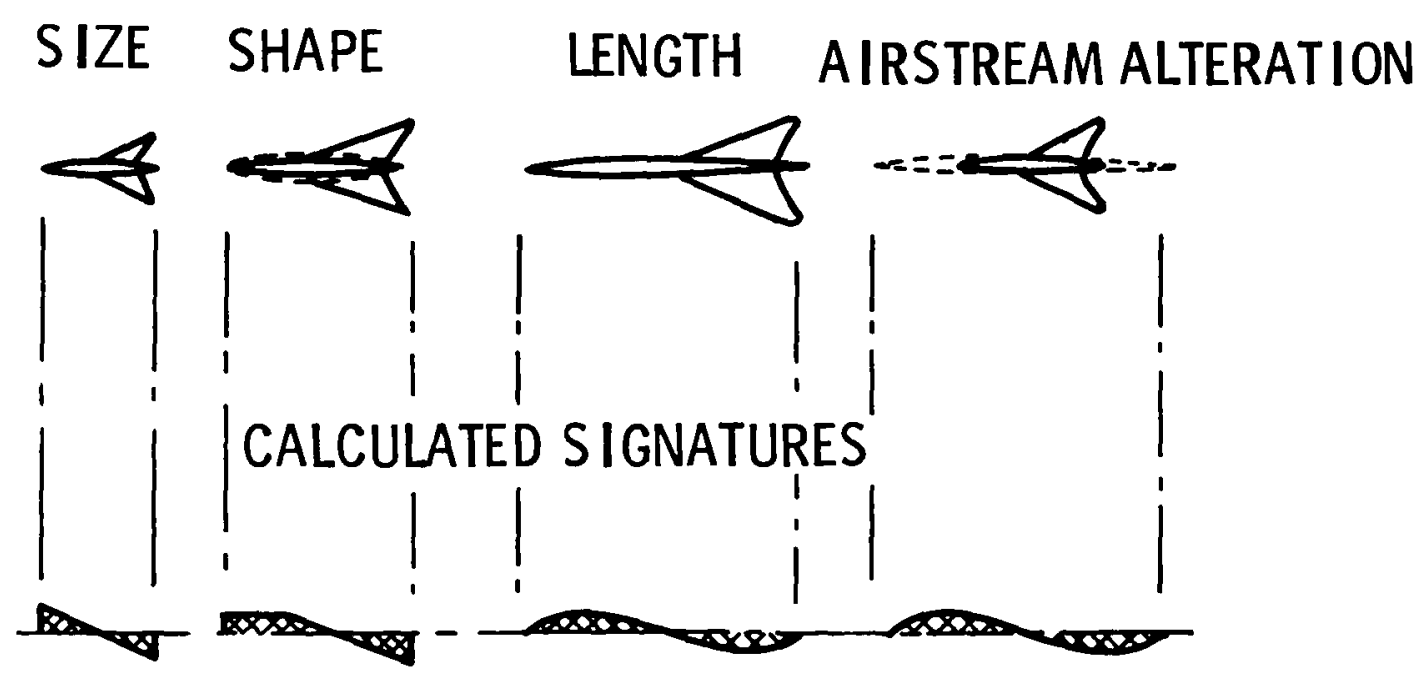

Figure 6.- Sonic boom minimization concepts . 


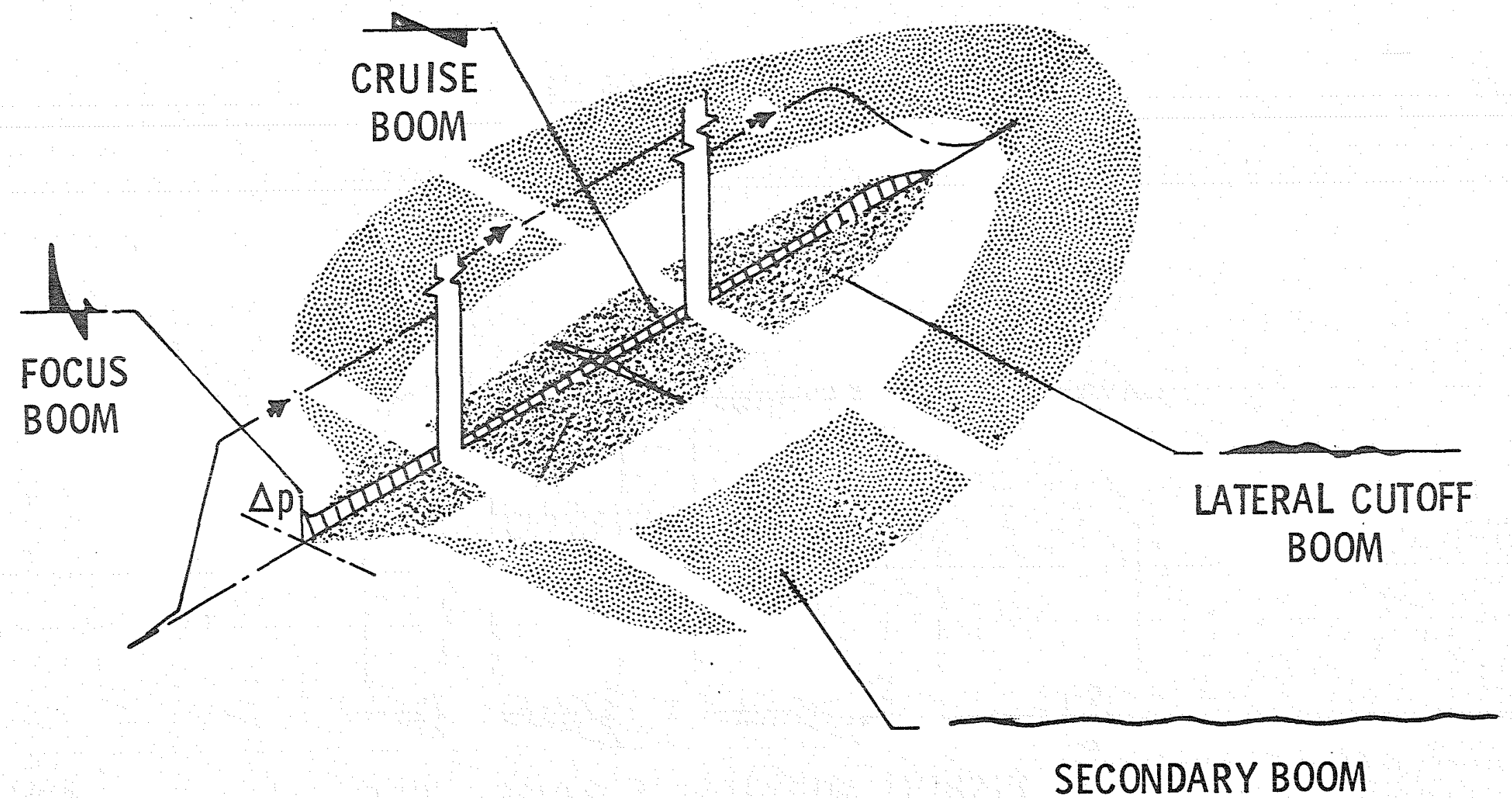

Figure 7.- Schematic of ground exposure carpets and sonic boom waveform characteristics. 

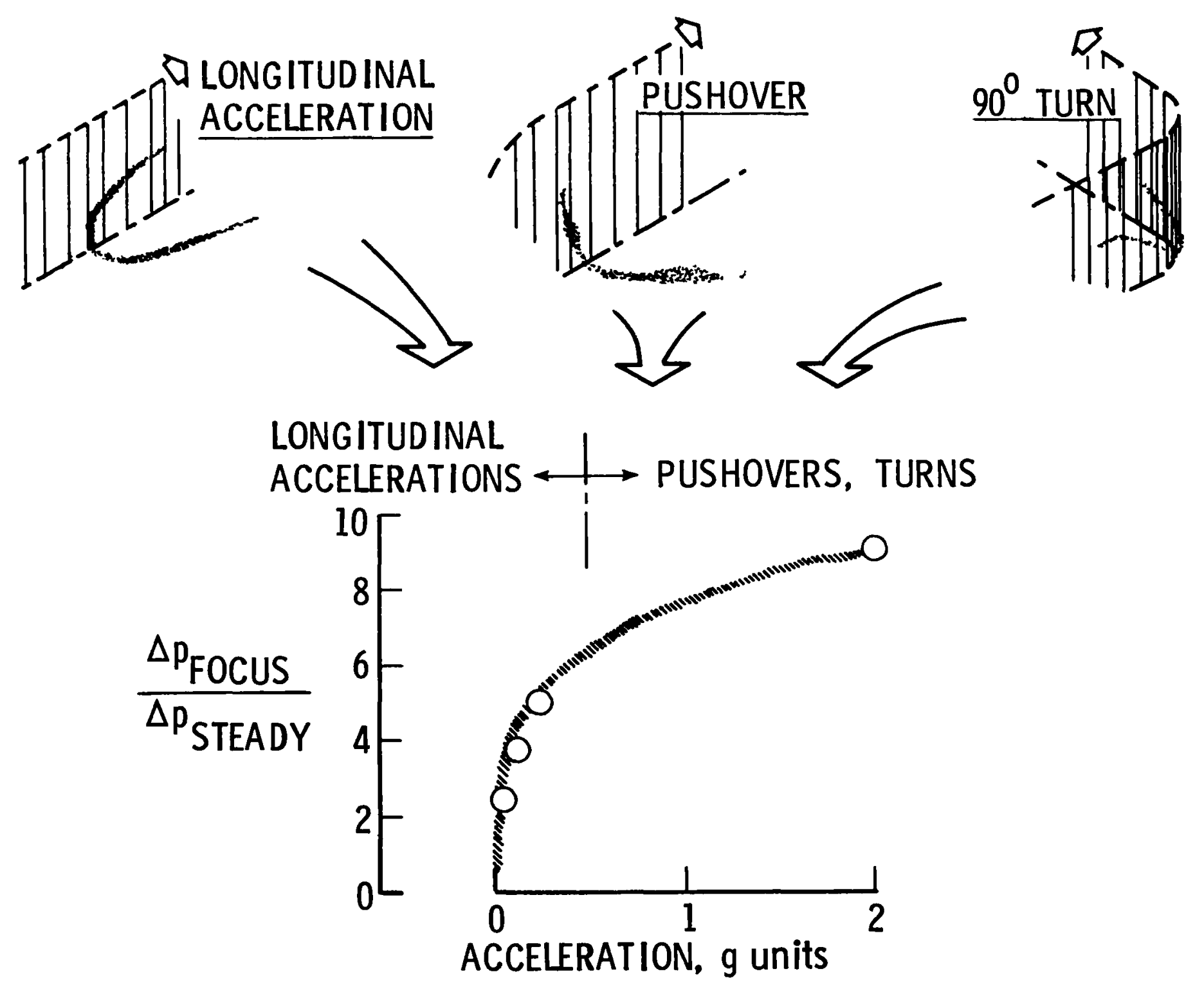

Figure 8.- Flight maneuvers and associated focus booms. 
NORMAL ATMOSPHERE

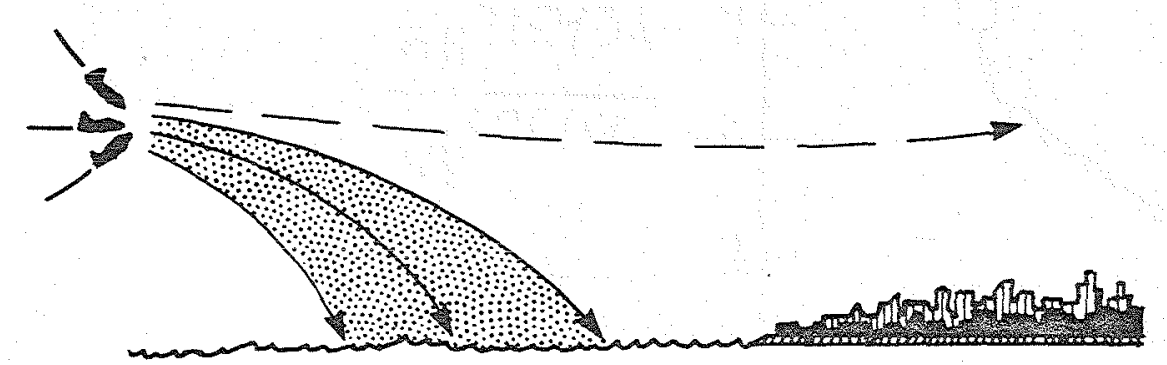

ABNORMAL ATMOSPHERE

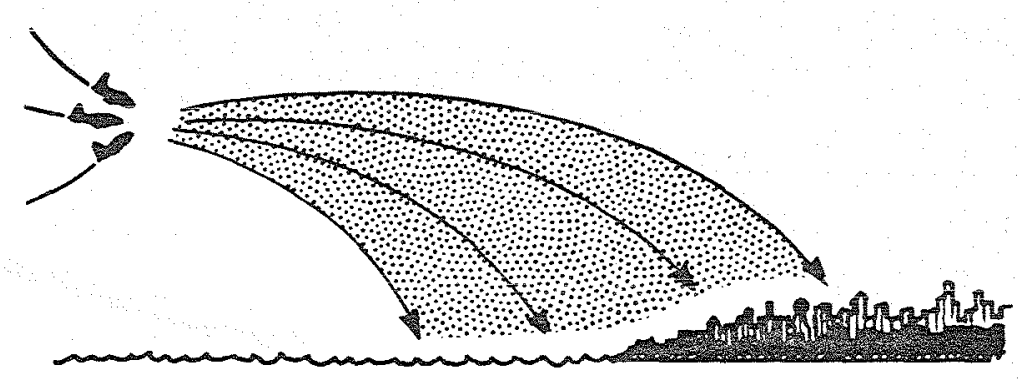

Figure 9.- Atmospheric refraction of maneuver booms. 
End of Document 